\title{
Design, analysis and fabrication of firewater storage tank
}

\author{
H. K. Sachidananda ${ }^{1}$ (D) Shalvi Dubey ${ }^{1} \cdot$ M. Veera Kumar ${ }^{1}$
}

(c) Springer Nature Switzerland AG 2018

\begin{abstract}
This research article focuses on the design, fabrication and analysis of firewater storage tank in order to assess tank integrity and maintaining compliance with industry and regulatory standards. The storage tank is considered of fixed cone roof firewater tank considering carbon steel as the material of the tank. The analysis has been carried out using CFD and finite element analysis. The results of the study shows that the designed tank is safe from the failure mode and the seismic energy transferred and accumulated in the structure.
\end{abstract}

Keywords Firewater tank · ANSYS · Design · Fabrication

\section{List of symbols}

$t_{\mathrm{d}} \quad$ Design shell thickness (mm)

$t_{\mathrm{t}} \quad$ Hydrostatic test shell thickness $(\mathrm{mm})$

D Nominal tank diameter $(\mathrm{m})$

$G \quad$ Design specific gravity of liquid

CA Corrosion allowance $(\mathrm{mm})=1.50$

$S_{d} \quad$ Maximum allowable stress ( $\left.\mathrm{MPa}\right)$

$S_{t} \quad$ Maximum allowable stress for hydrostatic condition (MPa)

$D_{\mathrm{i}} \quad$ Inside diameter of tank $(\mathrm{m})$

$H_{\mathrm{t}} \quad$ Hydrotest liquid level $(\mathrm{m})$

$H_{\mathrm{L}} \quad$ Design liquid level $(\mathrm{m})$

$V_{\mathrm{n}} \quad$ Maximum wind speed $(\mathrm{km} / \mathrm{h})$

$S_{p} \quad$ Peak ground acceleration for seismic analysis $=0.30$

I Importance factor $=1.25$

$L_{f} \quad$ Minimum roof live load (MPa)

$Y_{\mathrm{s}} \quad$ Minimum yield stress (MPa)

$U_{\mathrm{ts}} \quad$ Ultimate tensile stress (MPa)

$E \quad$ Modulus of elasticity (GPa)

$C_{f} \quad$ Yield stress reduction factor

$F_{\mathrm{y}} \quad$ Minimum yield stress (MPa)

$W_{1} \quad$ Force in annular plate $(\mathrm{N})$

$t_{\mathrm{ar}} \quad$ Minimum thickness without corrosion $(\mathrm{mm})$

$t_{\mathrm{ba}} \quad$ Minimum thickness of annular plate $(\mathrm{mm})$ $t \quad$ Top shell core thickness $(\mathrm{mm})$

$\mathrm{H}_{2} \quad$ Height of the tank (m)

$P_{\mathrm{w}} \quad$ Wind pressure (MPa)

$V \quad$ Wind speed

$P_{\mathrm{e}} \quad$ Design vacuum pressure

$E_{\mathrm{d}} \quad$ Young's modulus at design temperature and ambient temperature ( $\mathrm{MPa}$ )

$D_{\mathrm{v}} \quad$ Design vacuum pressure (MPa)

$C_{F} \quad$ Correction factor for velocity and vacuum

$H_{\mathrm{L}} \quad$ Maximum height of unstiffened shell (m)

$E_{\mathrm{a}} \quad$ Young's modulus at ambient temperature

$A_{\mathrm{v}} \quad$ Vertical seismic coefficient

$\mu \quad$ Friction coefficient for tank sliding

$G_{\mathrm{e}} \quad$ Effective specific gravity

$W_{\mathrm{i}} \quad$ Effective impulsive weight

$W_{\mathrm{p}} \quad$ Weight of tank contact (N)

$X_{\mathrm{i}} \quad$ Center of action $(\mathrm{m})$

$X_{c} \quad$ Center of attraction $(\mathrm{m})$

$X_{\mathrm{s}} \quad$ Height of the bottom of the shell to shell CG (m)

$W_{\mathrm{r}} \quad$ Total weight of the roof framing (N)

$X_{r} \quad$ Height from top of shell to roof CG (m)

$J \quad$ Anchorage ratio

$W_{\mathrm{rs}} \quad$ Roof loading acting on the shell per meter $(\mathrm{N} / \mathrm{m})$

\footnotetext{
$\triangle$ H. K. Sachidananda, sachidananda6@gmail.com; Shalvi Dubey, shalvidubey@gmail.com; M. Veera Kumar, veerakumar16@gmail.com | 'Department of Mechanical Engineering, School of Engineering and IT, Manipal Academy of Higher Education, Dubai Campus, Dubai, United Arab Emirates.
} 


$\begin{array}{ll}W_{\mathrm{tr}} & \text { Transposed width of each shell course }(\mathrm{mm}) \\ W & \text { Actual width of shell course }(\mathrm{mm}) \\ t_{\mathrm{uniform}} & \text { Corroded thickness of top shell }(\mathrm{mm}) \\ t_{\mathrm{actual}} & \text { Ordered thickness of each shell }(\mathrm{mm}) \\ H_{\mathrm{t}} & \text { Height of transposed width }(\mathrm{mm}) \\ \mathrm{H}_{\mathrm{f}} & \text { Height of product level }(\mathrm{mm}) \\ H & \text { Maximum design liquid level }(\mathrm{m}) \\ C_{\mathrm{i}} & \text { Coefficient of impulsive period } \\ t_{\mathrm{u}} & \text { Average thickness of shell (mm) } \\ T_{\mathrm{i}} & \text { Impulsive natural period, } \mathrm{s} \\ S_{\mathrm{p}} & \text { Peak ground acceleration } \\ R_{\mathrm{i}} & \text { Response reduction factor } \\ \mathrm{Q} & \text { Scaling factor } \\ F_{\mathrm{a}} \text { and } F_{\mathrm{V}} & \text { Site coefficient } \\ N & \text { Number of bolt } \\ P_{\mathrm{f}} & \text { Failure pressure, MPa } \\ M_{\mathrm{W}} & \text { Wind moment (N-m) } \\ F_{\mathrm{ba}} & \text { Bearing pressure (MPa) } \\ D_{\mathrm{bo}} & \text { Annular bottom plate diameter } \\ W_{\mathrm{o}} & \text { Operating weight (N) } \\ t_{\mathrm{br}} & \text { Annular bottom plate thickness }(\mathrm{mm}) \\ t_{\mathrm{b}} & \text { Annular bottom plate thickness }(\mathrm{mm}) \\ n_{\mathrm{c}} & \text { Effective width of the gusset (mm) } \\ t_{\mathrm{cr}} & \text { Thickness of chair plate } \\ N_{\mathrm{b}} & \text { Projection in chair plate } \\ C & \text { Spacing between the gussets } \\ P & \text { Bolt load on gusset } \\ f & \text { Bolt hole diameter (mm) } \\ M_{\mathrm{s}} & \text { Seismic overturning moment } \\ W_{\mathrm{i}} & \text { Effective impulsive weight of liquid (N) } \\ W_{\mathrm{s}} & \text { Weight supported by shell (N) }\end{array}$

\section{Introduction}

Storage tanks are used to store water, liquid petroleum, petroleum products and similar liquids. These tanks are designed as crack-free structures to eliminate any leakage. Oil storage tanks are susceptible to fire as it contains various hydrocarbons in it. Therefore, firewater tanks are installed in industries in case of emergency. The common materials used to construct firewater storage tanks are carbon steel, structural steel and concrete. Reservoir is a common term applied to liquid storage structure and it can be below or above the ground level. Reservoirs below the ground level are normally built to store large quantities of water, whereas those of overhead type are built for direct distribution by gravity flow and are usually of smaller capacity. Based on firewater tank, some of the literature reviews are as follows.

Scholz [1] has studied firewater storage, treatment, recycling and management. They reviewed firewater management and recycling of firewater in order to reduce water use. Also, they reviewed the health risk of firewater to firefighters and also to protect environment from pollution. Aware and Mathada [2] have studied cylindrical liquid storage tank using finite modeling techniques. They studied the seismic performance of various heights elevated water tanks using STAAD-PRO software, and they concluded that their study will be useful for civil engineers to understand the effects of various heights water tank. Kronowitt [3] has suggested an insulated water storage tank made of plastic along with associated piping and series of valves which is directly connected to the regular water supply which can be bypassed when not in use. Ali [4] has studied procedures for designing and assessing the firewater storage tank. They analyzed the procedure used in gravel pad foundation of firewater storage tank. They recommended conducting regular maintenance and installing instruments to monitor the settlement of the sand on which firewater storage tank is constructed. Palmer [5] has studied stresses in storage tanks. According to them, the settlement around the circumference of the foundation below the firewater storage tank can cause stressing and distortion resulting in deflections and stresses in the shell and the primary wind girder.

In this research paper, design and analysis of fixed cone roof firewater tank has been studied. The analysis of this tank has been performed using ANSYS static structural and CFD workbench for stress and pressure analysis, respectively, and validated. This analysis has been carried out for firewater tank considering steel, concrete and structural steel material.

\section{Methodology}

The firewater storage tank considered in this work is fixed cone roof tank. The material considered is carbon steel for the various parts such as shell courses, the roof plates, bottom and annular plates, wind girders and anchor bolts.

\section{Standards and specifications}

American petroleum institute (API) 650 [6] This standard establishes minimum requirements for material, design, fabrication, erection and inspection for vertical, cylindrical, aboveground, closed- and open-top, welded storage tanks in various sizes and capacities for internal pressures approximating atmospheric pressure, but a higher internal pressure is permitted when additional requirements are met. This standard applies only to tanks whose entire bottom is uniformly supported and to tanks in non-refrigerated service that have a maximum design temperature of $93^{\circ} \mathrm{C}\left(200^{\circ} \mathrm{F}\right)$ or less. 
National fire protection association (NFPA) 22 [7] This standard provides requirements for the design, construction, installation and maintenance of tanks and accessory equipment that supply water for private fire protection. Coverage includes provisions for: (1) gravity tanks, suction tanks, pressure tanks and embankment-supported coated fabric suction tanks, (2) towers, (3) foundations, (4) pipe connections and fittings, (5) valve enclosures, (6) tank filling and (7) protection against freezing.

American water works association (AWWA) D100 [8] The purpose of this standard is to provide guidance to facilitate the design, manufacture and procurement of welded carbon steel tanks for the storage of water. This standard does not cover all details of design and construction because of the large variety of sizes and shapes of tanks.

The main method used for determining the shell thickness of the liquid storage tanks designed is in conformance with API standard 650 is the one-foot method which is the most effective method for tanks with a smaller diameter.

The thickness of the cylindrical shell using one-foot method can be estimated as follows:

$t_{\mathrm{d}}=\frac{4.9 D(H-0.3) G}{S_{\mathrm{d}}}+C A$

$t_{\mathrm{t}}=\frac{4.9 D(H-0.3)}{S_{\mathrm{t}}}$

where $t_{\mathrm{d}}=$ design shell thickness $(\mathrm{mm}), t_{\mathrm{t}}=$ hydrostatic test shell thickness $(\mathrm{mm}), D=$ normal tank diameter $(\mathrm{m})$, $H=$ design liquid level $(\mathrm{m}), G=$ design specific gravity of liquid to be stored, $C A=$ corrosion allowance $(\mathrm{mm}), S_{d}=$ allowable stress for design condition (MPa), $S_{t}=$ allowable stress for the hydrostatic test condition $(\mathrm{MPa})$ and the minimum thickness of shell as per API 650 Cl.5.6.1.1 $=5.00 \mathrm{~mm}$.

The cylindrical shell designed for the tank comprises of five shell courses, the roof plate, the bottom plate and the annular plate. The details of the specifications are as follows:

Type of roof used is cone roof, contained fluid is firewater, specific gravity $G$ of the fluid is 1, operating pressure is atmospheric ( 1.01325 bar), operating temperature $=65^{\circ} \mathrm{C}$, design temperature $=0^{\circ}$ minimum and maximum $85^{\circ} \mathrm{C}$, inside diameter of tank (uncorroded), $D_{\mathrm{i}}=12.50 \mathrm{~m}$, tank height up to top of curb angle $H_{\mathrm{t}}=12.5 \mathrm{~m}$, design liquid level $H_{\mathrm{l}}=12.5 \mathrm{~m}$, tank filling height $H_{\mathrm{f}}=12 \mathrm{~m}$, nominal capacity $=1543 \mathrm{~m}^{3}$, stored capacity $=1473 \mathrm{~m}^{3}$, corrosion allowance (CA) for the shell, roof and bottom is $1.50 \mathrm{~mm}$, radiography for shell as per API $650 \mathrm{CL}$ 8.1.2, maximum wind speed $V_{\mathrm{n}}=190 \mathrm{~km} / \mathrm{h}$, peak ground acceleration for seismic analysis $S_{p}=0.30$, importance factor $I=1.25$ and minimum roof live load $L_{f}=0.0012 \mathrm{MPa}$.

\section{Material specifications (A36) and allowable stresses}

\subsection{For bottom shell courses and balance shell courses (As per A36) for shell design condition}

Minimum yield stress $\left(Y_{s}\right)=250 \mathrm{MPa}$, ultimate tensile stress $\left(U_{\mathrm{ts}}\right)=400 \mathrm{MPa}$, maximum allowable stress $\left(S_{\mathrm{d}}\right)=160 \mathrm{MPa}$, modulus of elasticity $(E)=200 \mathrm{GPa}$, yield stress reduction factor $\left(C_{\mathrm{f}}\right)=6.40$ and hydrotest temperature is taken as $17{ }^{\circ} \mathrm{C}$ (Table 1).

\subsection{For bottom shell courses and balance shell courses (As per A36) for shell hydrostatic condition}

Minimum yield stress $\left(Y_{s}\right)=250 \mathrm{MPa}$, ultimate tensile stress $\left(U_{\mathrm{ts}}\right)=400 \mathrm{MPa}$ and maximum allowable stress $\left(S_{t}\right)=171 \mathrm{MPa}($ Fig. 1, Tables 2, 3).

\subsection{Annular plate}

Material for the annular plate is selected as per A36 (Group III), minimum yield stress $\left(F_{\mathrm{y}}\right)=250 \mathrm{MPa}$. Maximum design liquid level $(H)=20 \mathrm{~m}$, force in annular plate $\left(W_{1}\right)$ due to liquid as per $\mathrm{C} 1 \cdot 5 \cdot 11.2=19,389 \mathrm{~N} / \mathrm{m}$, product stress in first shell course as per $\mathrm{C} 1.5 .5 .3=115.04 \mathrm{MPa}$, hydrostatic test stress in first shell course as per C1.5.5.3 $=93.47 \mathrm{MPa}$, minimum thickness without corrosion allowance $\left(t_{\mathrm{ar}}\right)=6 \mathrm{~mm}$, minimum thickness as per C1.5.11.2 $\left(t_{\mathrm{ar}}\right)=4.65 \mathrm{~mm}$, corrosion allowance for annular plate $(C A)=1.50 \mathrm{~mm}$. Therefore, $t_{\mathrm{ar}}+\mathrm{CA}=7.50 \mathrm{~mm}$, provided thickness of annular plate $\left(t_{\mathrm{ba}}\right)=8 \mathrm{~mm}$, mean diameter $D=12.508 \mathrm{~m}$, minimum annular bottom plate width inside of shell $=600 \mathrm{~mm}$, lap of bottom annular plate $=50 \mathrm{~mm}$, minimum required radial width $=708 \mathrm{~mm}$, required annular bottom plate width $=384.60 \mathrm{~mm}$ and provided width of annular plate $=720 \mathrm{~mm}$.

Table 1 Maximum allowable stress for bottom shell course (design condition) ( $S_{d}$ should be the smallest of A, B and C.)

\begin{tabular}{lll}
\hline$A$ & $B$ & $C$ \\
\hline$S_{d}=\frac{2}{3} C_{f} Y_{s}=1066.67 \mathrm{MPa}$ & $S_{d}=\frac{2}{5} U_{\mathrm{ts}}=160 \mathrm{MPa}$ & $S_{d}=($ API 650$)=160 \mathrm{MPa}$
\end{tabular}




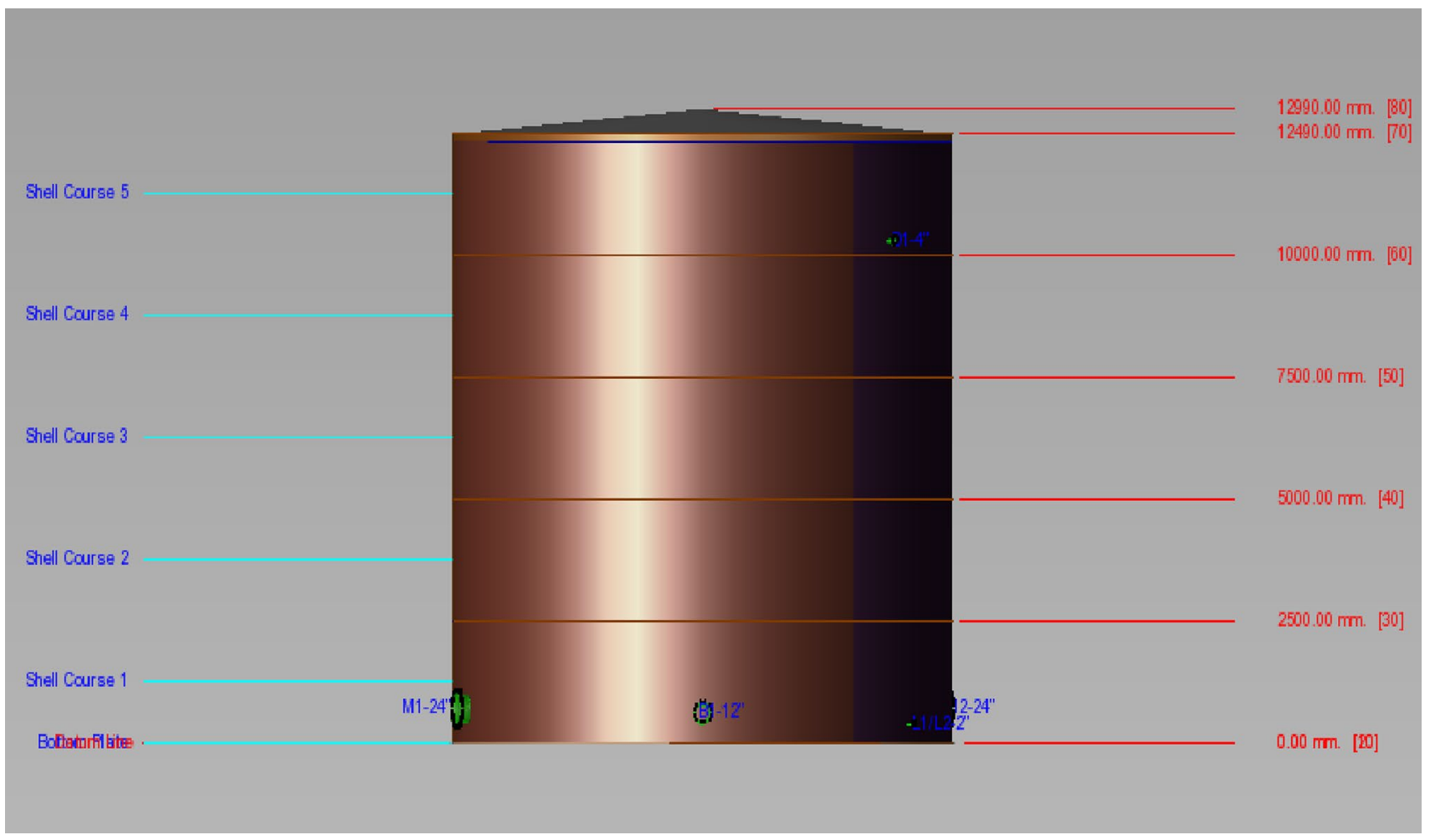

Fig. 1 Firewater tank elevation and shell courses

\subsection{Bottom plate}

Corrosion allowance for bottom plate $(C A)=1.50 \mathrm{~mm}$, minimum required thickness as per C1.5.4.1 $=6 \mathrm{~mm}+\mathrm{CA}=7.50 \mathrm{~mm}$, provided thickness of bottom plate $=8 \mathrm{~mm}$ and resisting downward force due to bottom plate corroded weight $=51.03 \mathrm{~kg} / \mathrm{m}^{3}$.

\subsection{Roof plate}

Type of roof used is cone roof and the roof slope/ angle $=4.76^{\circ}$, nominal diameter of tank $D=12.508 \mathrm{~m}$, corrosion allowance for roof plate $(C A)=1.50 \mathrm{~mm}$ and the load considered is $0.002171 \mathrm{MPa}$.

The minimum thickness (C1.5.10.5.1) for self-supporting cone roof is calculated as given in equation below.

$\left[\left(\frac{D}{4.8 \sin 4.76}\right)\left(\frac{T}{2.2}\right)^{0.5}\right]+C A=32.67 \mathrm{~mm}$
This thickness is not practical and hence supported cone roof is considered for which minimum roof plate thickness considered is $8 \mathrm{~mm}$.

\subsection{Intermediate wind girders (API-650 C1 1.5.9.7 and M.6)}

The tank nominal diameter $(D)=12.508 \mathrm{~m}$, corrosion allowance for the shell $(C A)=1.50 \mathrm{~mm}$, top shell course thickness corroded $t=4.50 \mathrm{~mm}$, height of tank including free board $\left(H_{2}\right)=12.50 \mathrm{~m}$, maximum wind velocity $\left(V_{\mathrm{m}}\right)=190 \mathrm{~km} / \mathrm{h}$, design wind speed as per 5.2.1 $=1.2 \mathrm{~V}=228 \mathrm{~km} / \mathrm{h}$, wind pressure $\left(P_{\mathrm{w}}\right)$ on cylindrical part $=$ $0.86 \frac{\mathrm{V}}{190} \frac{\mathrm{V}}{190} \times 1000=1238.40 \frac{\mathrm{N}}{\mathrm{m}^{2}}$, design vacuum pressure $\left(P_{\mathrm{e}}\right)=0.00 \mathrm{~N} / \mathrm{m}^{2}$, total external pressure $\left(P_{\mathrm{w}}+P_{\mathrm{e}}\right)=1238.40 \mathrm{~N} /$ $\mathrm{m}^{2}$, design temperature $(T)=85^{\circ} \mathrm{C}$, Young's modulus at design temperature and ambient temperature $E_{\mathrm{d}}=200 \mathrm{GPa}$, design vacuum $\left(D_{\mathrm{v}}\right)=0.000 \mathrm{MPa}$, the vacuum already considered as per C1.5.9.7.1.1 $=0.00024 \mathrm{MPa}$, correction factor (CF) for velocity and vacuum $=0.720$, maximum height $\left(H_{1}\right)$ of unstiffened shell in corroded condition (C1.5.9.7.1)

Table 2 Maximum allowable stress for bottom shell course (hydrostatic test condition) $\left(S_{t}\right.$ should be the smallest of $A, B$ and $C$.)

\begin{tabular}{lll}
\hline$A$ & $B$ & $C$ \\
\hline$S_{t}=\frac{3}{4} C_{f} Y_{s}=1200 \mathrm{MPa}$ & $S_{t}=\frac{3}{7} U_{t s}=171.43 \mathrm{MPa}$ & $S_{t}=(\mathrm{API} 650)=171 \mathrm{MPa}$ \\
\hline
\end{tabular}




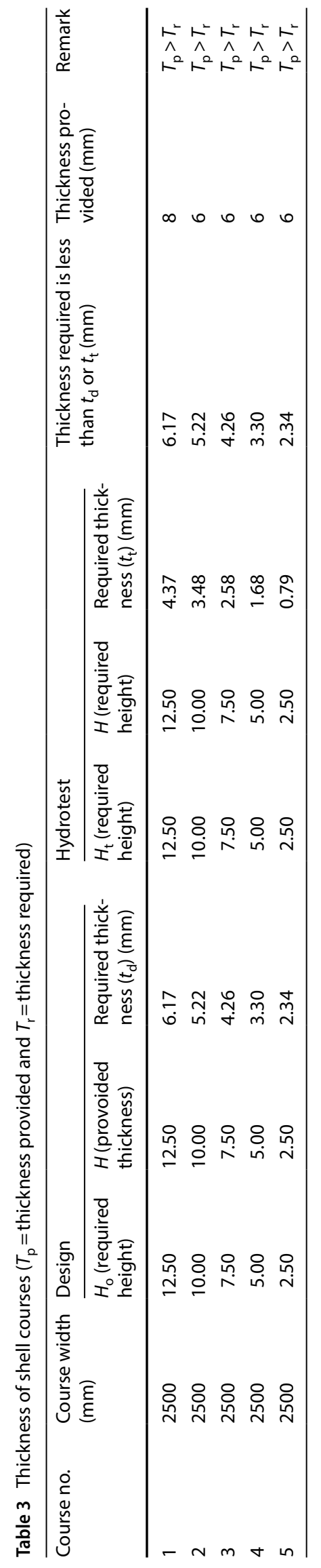

Table 4 Thickness of each course shell and transposed width

\begin{tabular}{llll}
\hline Shell course no. & Course width $(\mathrm{m})$ & $t_{\text {actual }}(\mathrm{m})$ & $W_{\mathrm{tr}}(\mathrm{m})$ \\
\hline 1 & 2.50 & 6.50 & 0.997 \\
2 & 2.50 & 4.50 & 2.500 \\
3 & 2.50 & 4.50 & 2.500 \\
4 & 2.50 & 4.50 & 2.500 \\
5 & 2.50 & 4.50 & 2.500 \\
\hline
\end{tabular}

$=9.47 \times \sqrt{\frac{t^{3}}{d^{3}}} \times \frac{E_{\mathrm{d}}}{E_{\mathrm{a}}}=12.772 \mathrm{~m}$ and transposed width of each shell course C1.5.9.7.2 $W_{\mathrm{tr}}=W \times \sqrt{\frac{t_{\text {uniform }}^{5}}{t_{\text {actual }}^{5}}}$ where $W=$ actual width of shell course $(\mathrm{mm}), t_{\text {uniform }}=$ corroded thickness of top shell $=4.5 \mathrm{~mm}$ and $t_{\text {actual }}=$ ordered thickness of each shell course $(\mathrm{mm})$ (Table 4$)$.

Since the height of transformed shell $\left(H_{t}\right)$ is equal to the sum of the transposed width of the courses and since $H_{1}$ is less than $H_{\mathrm{t}}$, intermediate wind girder is required as per CL.5.9.7.3. So number of wind girders required will be equal to one. Therefore, distance between IWG and top angle $H_{1}=5.50 \mathrm{~m}$, required modulus of section $(Z)=\frac{D^{2} H_{1}}{17} \times\left(\frac{V}{190}\right)^{2}=50.60 \mathrm{~cm}^{3}$ and the provided modulus of section $=97.89 \mathrm{~cm}^{3}$.

\subsection{Seismic analysis (API 650)}

Height of product level $\left(H_{\mathrm{F}}\right)=12 \mathrm{~m}$, ratio $D / H=1.042$, ratio $H / D=0.959$, coefficient of impulsive period $\left(C_{\mathrm{i}}\right)=6.14$, average thickness of shell (uncorroded) $t_{\mathrm{u}}=6.40 \mathrm{~mm}$ and impulsive natural period (as per C1E4.51.1) is calculated as follows:

$T_{\mathrm{i}}=\frac{C_{\mathrm{i}} H \rho^{0.5}}{2000^{0.5} \frac{t_{\mathrm{u}}^{0.5}}{D^{0.5}} E^{0.5}}=0.163 \mathrm{~s}$

Similarly, peak ground acceleration $\left(S_{p}\right)=0.340$, response reduction factor $\left(R_{\mathrm{i}}\right)=3$ and scaling factor $q=1, S_{1}=0.260$ and $S=8$. The site coefficient $F_{\mathrm{a}}$ and $F_{\mathrm{v}}$ as per table E-1, E-2 is considered as 1 and 1.5, impulsive horizon seismic coefficient $\left(A_{\mathrm{i}}\right)$ is calculated using $2.5 \times Q \times F_{\mathrm{a}} \times S_{\mathrm{p}} \times \frac{1}{R}=0.283$, vertical seismic coefficient $\left(A_{v}\right)=0.1190$, convective (sloshing) period $\left(T_{\mathrm{C}}\right)$ is calculated using $T_{C}=1.8 K_{S} D^{0.5}$ as per C1.E.4.5.2- $\mathrm{a}=3.6827 \mathrm{Sec}, K_{\mathrm{s}}=\frac{0.578}{\sqrt{\tanh \left(\frac{3.68 \mathrm{H}}{D}\right)}}=0.5785, K=1.5$, $T_{1}=8 \mathrm{~s}, T_{\mathrm{s}}=0.4588 \mathrm{~s}$, friction coefficient for tank sliding $\mu=0.40$, convective horizontal seismic coefficient for $T_{\mathrm{c}}<4 \mathrm{~s}$, effective specific gravity $\left(G_{\mathrm{e}}\right)=G\left(1-0.4 A_{\mathrm{v}}\right)=0.95$ and effective impulsive weight of liquid as per E6.1.1 is 
calculated using $W_{\mathrm{i}}=\left[1-0.218 \frac{D}{H}\right] W_{\mathrm{p}}$ where $W_{\mathrm{p}}$ is the weight of tank content $=14,445,195 \mathrm{~N}$, but $D / H<1.333$ as per E.6.6.6. Similarly, the center of action for ringwall foundation as per E6.1.2.1 is calculated using $X_{\mathrm{i}}=\left[0.5-0.094 \frac{D}{H}\right] H=4.824 \mathrm{~m}$, effective convective weight of liquid $\left(W_{\mathrm{c}}\right)$ as per E6.1.1 is calculated using $W_{\mathrm{c}}=\left[0.23 \frac{\mathrm{D}}{\mathrm{H}} \tanh \left(3.67 \frac{\mathrm{H}}{\mathrm{D}}\right)\right] W_{\mathrm{p}}=345,699 \mathrm{~N}$, center of attraction $\left(X_{c}\right)$ for ringwall foundation is calculated as per E6.1.2.1 $X_{c}=\left[1-\cosh \left(3.67 \frac{H}{D}\right)-\frac{1}{3.67 \frac{H}{D} \sinh \left(3.67 \frac{H}{D}\right)}\right] H$ $=8.788 \mathrm{~m}$, the seismic overturning moment $\left(M_{\mathrm{S}}\right)$ at the base of the tank for ringwall condition $M_{\mathrm{S}}=\left[A_{\mathrm{i}}\left(W_{\mathrm{i}} X_{\mathrm{i}}+W_{\mathrm{S}} X_{\mathrm{S}}+W_{\mathrm{r}} X_{\mathrm{r}}\right)\right]^{2}+\left(\left[A_{\mathrm{c}}\left(W_{\mathrm{c}} X_{\mathrm{c}}\right)\right]^{2}\right)^{0.5}=1$ $6,062,990 \mathrm{~N}-\mathrm{m}$, shear force due to seismic $F_{\mathrm{S}}=\left\{A_{\mathrm{i}}\left(W_{\mathrm{i}}+W_{\mathrm{s}}+W_{\mathrm{r}}+W_{\mathrm{f}}\right)^{2}+\left(A_{\mathrm{c}}\left(W_{\mathrm{c}}\right)^{2}\right\}^{0.5}=3,315,745 \mathrm{~N}\right.$, Anchorage ratio $(J)=\frac{M_{\mathrm{s}}}{D^{2}\left(W_{\mathrm{t}}(1-0.4 A V)+W_{\mathrm{a}}-0.4 W_{\text {int }}\right)}$ where $W_{\mathrm{t}}=\left[\frac{W_{\mathrm{s}}}{\pi D}+W_{\mathrm{rs}}\right]$ and roof loading acting on shell $\left(W_{\mathrm{rs}}=\frac{W_{\mathrm{r}}}{\pi D}\right)$ and $W_{\mathrm{a}}=99 \times t_{\mathrm{a}} \sqrt{F_{\mathrm{y}} G_{\mathrm{e}} H}, W_{\text {int }}=0.0 \mathrm{~N} / \mathrm{m}$.

The maximum shell compression for mechanically anchored tank

$\sigma_{\mathrm{C}}=\left(W_{\mathrm{t}}\left(1+0.4 A_{\mathrm{v}}\right)+\frac{1.273 \mathrm{Mrw}}{D^{2}}\right) \times \frac{1}{1000 t_{\mathrm{s}}}$

And the allowable shell compression (Fc) is calculated using

$\frac{G H D^{2}}{t^{2}}$
And the condition is maximum shell compression should be less than allowable shell compression (Tables 5 , 6).

\subsection{Anchor bolt design}

The number of anchor bolt used $N=20$ and the material for the bolt considered is cast iron and the yield stress of anchor bolt $\left(F_{\mathrm{y}}\right)$ is considered as $250 \mathrm{MPa}$. The failure pressure $\left(P_{f}\right)$ of the bolt is calculated using the following equation $P_{f}=\left(1.6 P-\left(\frac{0.000746 \times D L R}{D}\right)\right)$ where DLR is the dead load of shell other than roof (corroded), dead load including roof (corroded) and dead load other than roof. The design pressure is calculated using $\left[(P-0.8\right.$ th $\left.) \times D^{2} \times 785\right]-W_{1}$ and the test pressure $\left[\left(P_{\mathrm{t}}-0.8\right.\right.$ th $\left.) \times D^{2} \times 785\right]-W_{1}$ and the failure pressure is calculated using $\left[\left(1.5 \times P_{f}-0.08\right.\right.$ th $\left.) \times D^{2} \times 785\right]-W_{3}$ and the wind load is $\left[P_{W R} \times D^{2} \times 785+\frac{4 M_{\mathrm{W}}}{D}\right]-W_{2}$ and the seismic load is calculated using $\left[\left(\frac{4 M_{S}}{D}\right)-W_{2}\left(1-0.4 A_{v}\right)\right]$. Also, design pressure + wind is calculated using $\left[\left(0.4 P+P_{W R}-0.08\right.\right.$ th $\left.) \times D^{2} \times 785\right]+\left[\frac{4 M_{\mathrm{w}}}{D}\right]-W_{1}$ and the design pressure + seismic is calculated using $\left[(0.4 P-0.08\right.$ th $\left.) \times D^{2} \times 785\right]+\left[\frac{4 M_{s}}{D}\right]-W_{2}\left(1-0.4 A_{v}\right)$ and the frangibility pressure is calculated using $\left[(3 P F-0.08\right.$ th $\left.) \times D^{2} \times 785\right]-W_{3}$.

\subsection{Design of annular bottom plate}

The bearing pressure $\left(F_{\text {be }}\right)$ operating condition is calculated using $\frac{4 W_{0}}{\pi D_{\mathrm{bo}}^{2}}$ where $D_{\text {bo }}$ is the annular bottom plate
Table 5 Dynamic hoop tensile stresses due to seismic motion of liquid
Table 6 Dynamic hoop stress for $D / H<1.33$

\begin{tabular}{llllllll}
\hline Firewater tank & $Y(\mathrm{~m})$ & $N_{\mathrm{i}}(\mathrm{N} / \mathrm{mm})$ & $N_{\mathrm{c}}(\mathrm{N} / \mathrm{mm})$ & $N_{\mathrm{h}}(\mathrm{N} / \mathrm{mm})$ & $\sigma_{\mathrm{t}}(\mathrm{MPa})$ & Allowable $\sigma_{\mathrm{t}}(\mathrm{MPa})$ & Result \\
\hline Shell course 1 & 12 & 131.06 & 1.17 & 717.08 & 134.38 & - & OK \\
Shell course 2 & 9.5 & 123.71 & 1.64 & 563.86 & 156.68 & 212.80 & OK \\
Shell course 3 & 7 & 105.86 & 3.04 & 410.64 & - & 212.80 & OK \\
Shell course 4 & 4.5 & 77.50 & 6.15 & 257.41 & - & 212.80 & OK \\
Shell course 5 & 2 & - & 12.76 & 104.19 & 32.61 & 212.80 & OK \\
\hline
\end{tabular}

\begin{tabular}{llllllll}
\hline Firewater tank & $Y(\mathrm{~m})$ & $N_{\mathrm{i}}(\mathrm{N} / \mathrm{mm})$ & $N_{\mathrm{c}}(\mathrm{N} / \mathrm{mm})$ & $N_{\mathrm{h}}(\mathrm{N} / \mathrm{mm})$ & $\sigma_{\mathrm{t}}(\mathrm{MPa})$ & Allowable $\sigma_{\mathrm{t}}(\mathrm{MPa})$ & Result \\
\hline Shell course 1 & 12 & 115.10 & 1.17 & 717.08 & 132.37 & - & OK \\
Shell course 2 & 9.5 & 115.10 & 1.64 & 563.86 & - & - & OK \\
Shell course 3 & 7 & 108.13 & 3.04 & 410.64 & - & 212.80 & OK \\
Shell course 4 & 4.5 & - & 6.15 & 257.41 & 77.18 & 212.80 & OK \\
Shell course 5 & 2 & 44.04 & 12.76 & 104.19 & 33.71 & 212.80 & OK \\
\hline
\end{tabular}




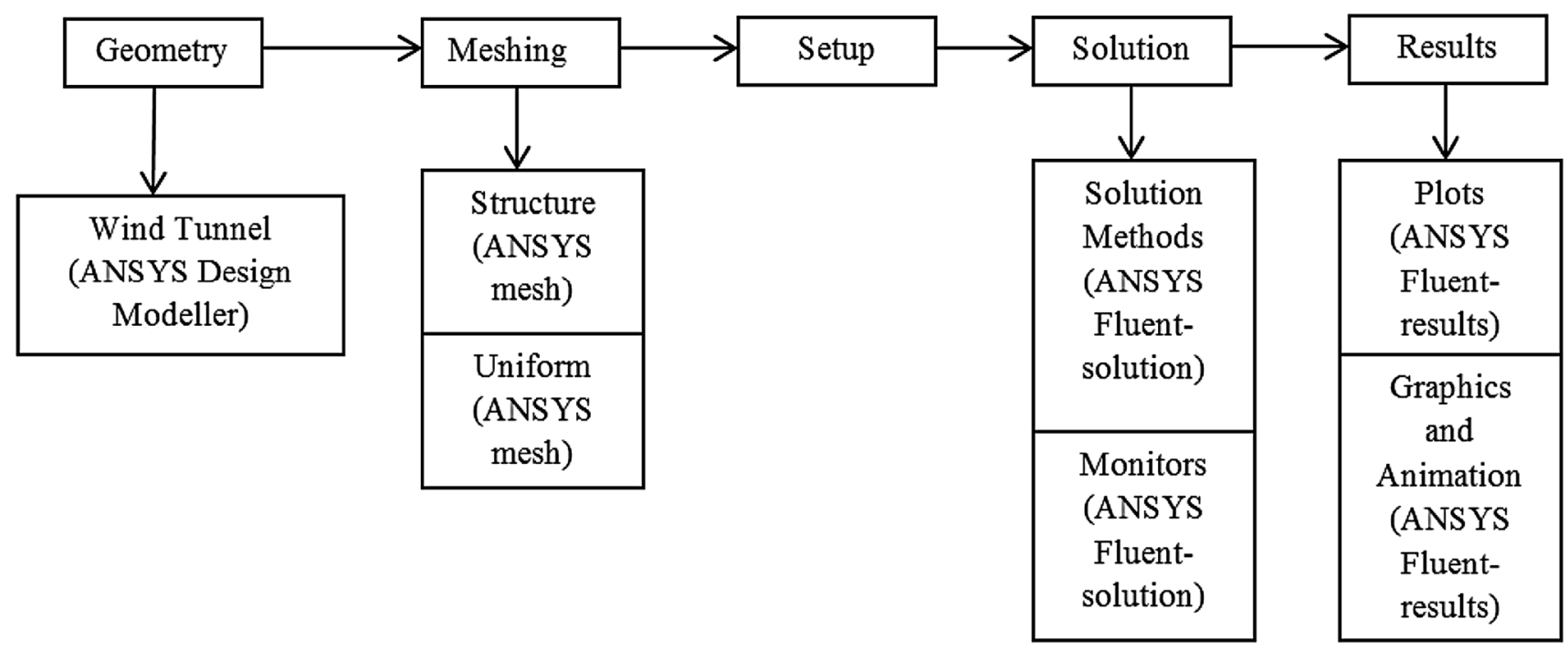

Fig. 2 Main steps for CFD analysis

outer diameter and $W_{\mathrm{o}}$ is the operating weight. The required annular bottom plate thickness $\left(t_{\mathrm{br}}\right)$ is calculated using $\left[N_{\mathrm{p}} \times \sqrt{\frac{f_{\mathrm{be}}}{t_{\mathrm{b}}}}\right]$ where $\mathrm{t}_{\mathrm{b}}$ is the annular bottom plate thickness.

Table 7 Mesh description

\begin{tabular}{ll}
\hline Area firewater tank & \\
\hline Mesh type & Tetrahedron mesh \\
Scale factor & 1 \\
Nodes & 17,408 \\
Elements & 15,075 \\
\hline
\end{tabular}

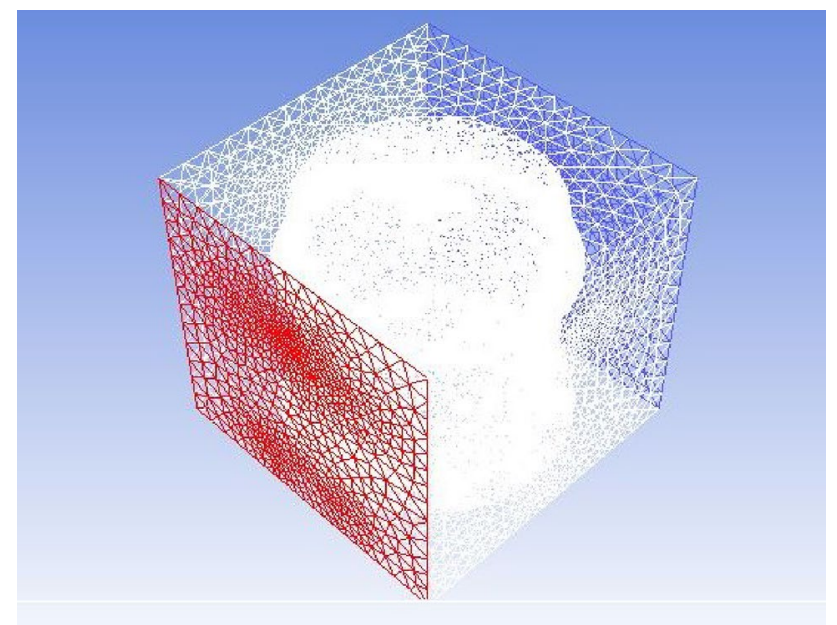

Fig. 3 Meshing of geometry

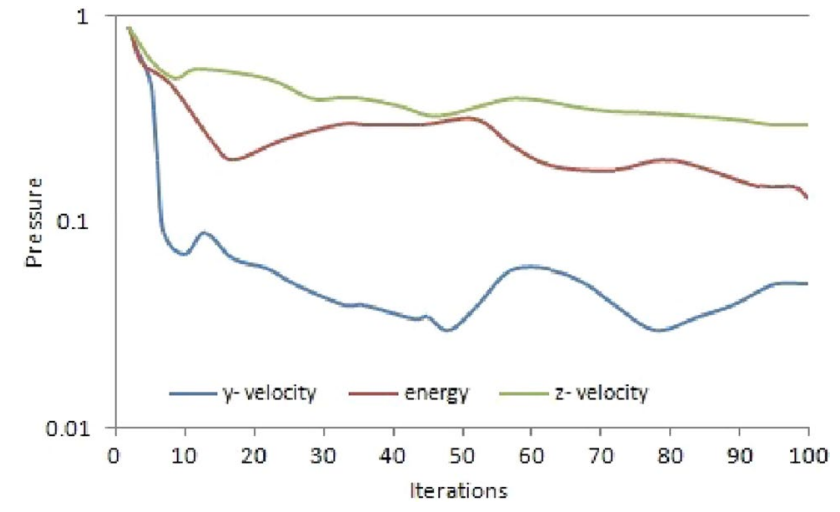

Fig. 4 Graph of iteration/time step

\subsection{Design of vertical gusset}

The effective cross section of the gusset is calculated using $\left[t_{\mathrm{v}}\left(n_{\mathrm{c}}-0.25\right)\right]$ where $t_{\mathrm{v}}$ is the thickness of the gusset and the radius of gyration of the gusset is calculated using $0.289 t_{\mathrm{v}}$ and the column formula as per AISI is given as $\frac{P}{2 a}<17000-0.485\left(\frac{L^{2}}{r^{2}}\right)$ where $P / 2 a$ is the minimum bolt load on the gusset.

\subsection{Design of anchor bolt chair plate}

The required thickness of chair plate $t_{\mathrm{cr}}=C A+$ $\left[\frac{P C}{4 S_{b}\left(N_{b}-f\right)}\right]^{0.5}$ where $N_{b}$ is the projection on chair plate, $C$ is the spacing between the gusset, $P$ is the bolt load on gusset and $f$ is the bolt hole diameter. 


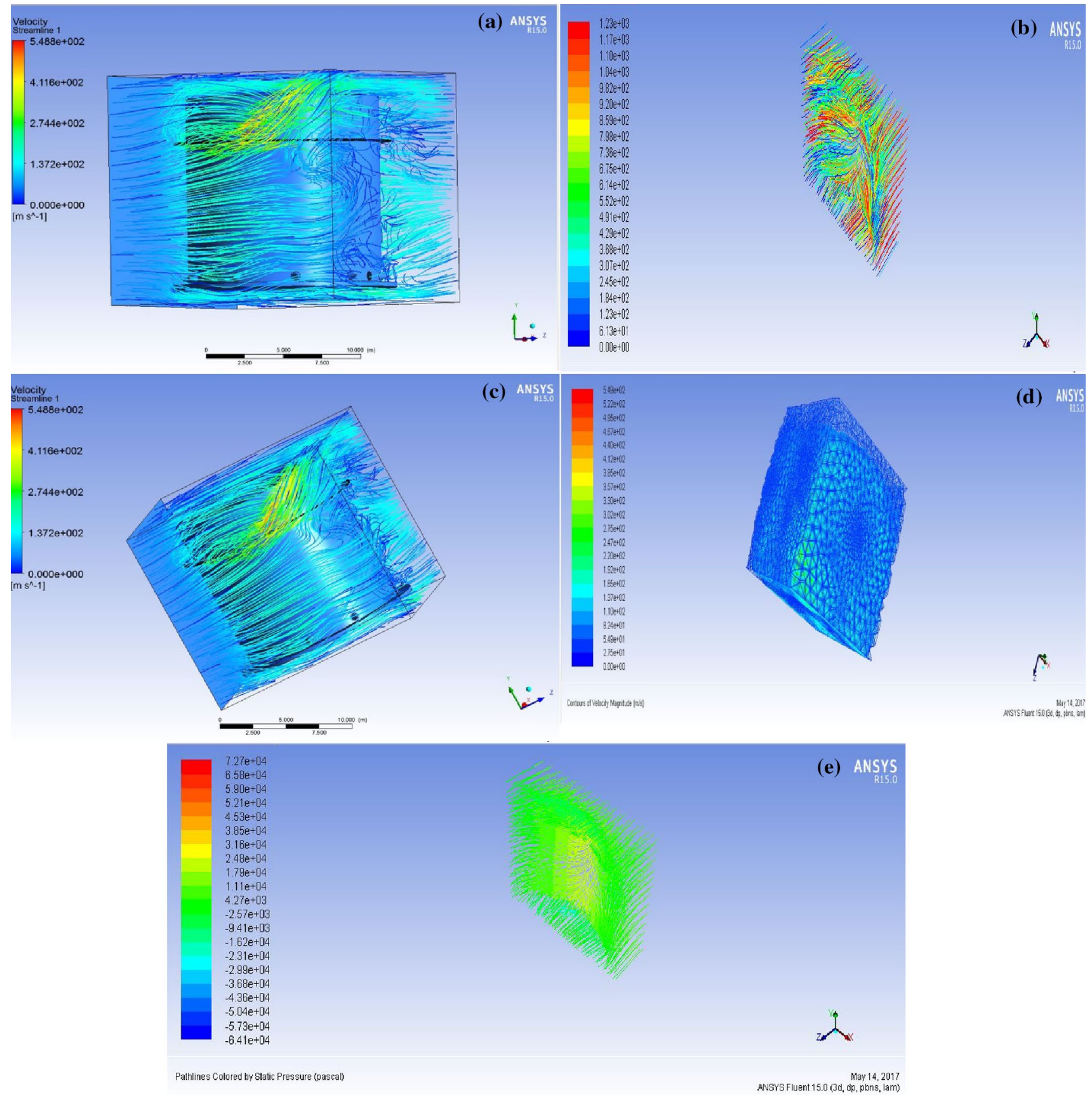

Fig. 5 a Velocity contour and velocity at the inlet. b Path lines of the tank. c CFD flow analysis of fixed roof tank. d Contours of velocity magnitude of fixed cone roof tank and e path lines by static pressure of fixed cone roof tank

\section{Results and analysis}

\subsection{Computational fluid dynamic analysis}

Computational fluid dynamics (CFD) is a branch of fluid mechanics that uses numerical analysis to solve and analyze fluid flow problem. CFD analysis has been used to analyze the fluid flow in case of firewater storage tank. CFD analysis gives a subjective and quantitative forecast of liquid by method of mathematical modeling, numerical method and software tools. In this research work, the calculations and design considerations of the wind tunnel using the solid work software as well as ANSYS 15.0 workbench are used. The different steps for CFD analysis can be achieved as shown in Fig. 2. ANSYS software was utilized for meshing of the geometry. Appropriate parameters for the cross section have been chosen to obtain geometry and state of the model.

\section{SN Applied Sciences}


The firewater storage tank has been mapped meshed, and then the analysis to the solution stage using the fluent module of ANSYS 15.0 has been performed [9]. The mesh description, mesh type, scale factor and the number of elements used to construct firewater tank have been shown in Table 7, and the corresponding meshing of geometry is as shown in Fig. 3.

The solution is obtained using an iterative approach in fluent solver 15.0. This method allows the software to do iterations till the expected converging criteria are defined and the corresponding graph of iterations is as shown in Fig. 4. From Fig. 4, it is observed that the number of iterations performed has shown that the expected converging criteria are performed as per the requirement. The different colors show the convergence rate for each solved equation considering velocity and energy.

\subsection{CFD Simulation results}

The simulation of pressure, the flow velocity and the streamlines for the designed tank were carried out using ANSYS 15 workbench software considering a wind speed of $230 \mathrm{~km} / \mathrm{h}$. The subsequent graphs of the results were then obtained.

Figure $5 \mathrm{a}$ shows the velocity at the inlet of the tank, and from this figure it is observed that flow velocity is irregular all through the cross section. It is also observed that the highest flow velocity is measured at the center of the cross section and steadily decreases toward the boundary surface. Figure $5 \mathrm{~b}$, e shows the static pressure of the tank where it is found that the inlet has the maximum pressure readings while the central zone of settling chamber experiences a touch of static pressure drop and occurs due to turbulence at the entrance of the chamber. Due to low levels of pressure at the test section exit, no boundary layer thickening at the length of the test chamber walls was found and hence makes a better tank quality. Figure $5 \mathrm{c}$ shows the velocity traveling from the inlet toward the tank at a speed of around $230 \mathrm{~km} / \mathrm{h}$, and it is observed that the streamlines and the points at which the air impacts the most and the least can be estimated and the contours of velocity and magnitude of velocity of fixed cone roof tank are as shown in Fig. $5 \mathrm{~d}$.

\subsection{Static structural analysis}

Static structural analysis of the firewater storage tank has been performed using mechanical APDL workbench that takes care of the numerical examination and calculations of the forces and loads. A static structural analysis was carried on the tank with a load of $5000 \mathrm{~N}$ acting on it and keeping the base as a fixed support. A similar analysis was carried out for loads and pressures of different magnitudes, and the obtained results were obtained and observed. For this research work, the calculations and design considerations of the tank have been completed using solid works as well as ANSYS 15 workbench software and the material used is carbon steel. Figure 6 shows the model of the firewater storage tank constructed using ANSYS. The details of the model are as shown in Table 8.

A static structural analysis was carried on a tank with a load of $5000 \mathrm{~N}$ by considering fixed support as the base. In order to obtain the geometry, mapped meshing has been performed using ANSYS. Figure $7 a$, $b$ shows the equivalent von Mises stress diagram and total deformation diagram for the firewater tank for the carbon steel material. It is clear from the graphs that red color shows the highest magnitude whereas blue color shows the lowest magnitude of stresses. From Fig. 7b, it is observed that the deformation occurs near the center of the impacted area and is the area which has undergone the maximum contact from the incoming force. In this region, the maximum deformation occurred is close to $2.702 \mathrm{~m}$ whereas the bottom of the tank remains unaffected as it is fixed.

Figure 8a shows the graphical representation of absolute pressure at different points on inlet, wall and outlet. From this figure, it is observed that the dynamic pressure is the highest when the position of the inlet is near $0 \mathrm{~m}$ and subsequently decreases as the position of inlet moves away from the center. Figure $8 \mathrm{~b}$ shows the static pressure at different points on inlet, wall and outlet and the static pressure is the highest when the position of the inlet is near $0 \mathrm{~m}$. Figure $8 \mathrm{c}-\mathrm{e}$ shows the pressure coefficient, dynamic pressure and the total pressure at different points on inlet, wall and outlet. From all these figures, it is observed that the pressure is the highest when the position of inlet is $0 \mathrm{~m}$ and decreases as the position of inlet moves away from the center. Figure $8 \mathrm{f}-\mathrm{i}$ shows the graph

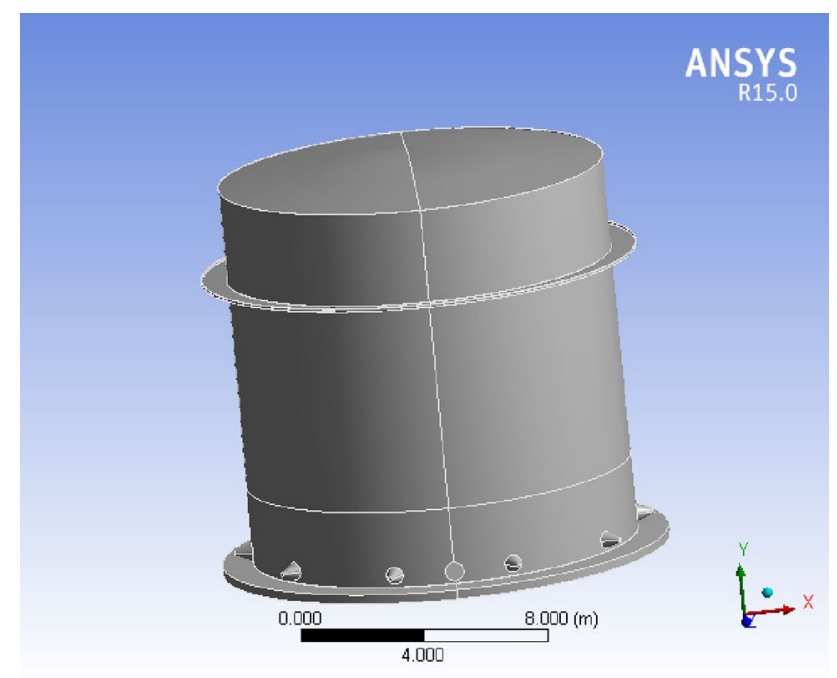

Fig. 6 Firewater storage tank model using ANSYS 
Table 8 Geometric properties

\begin{tabular}{ll}
\hline Geometry bounding box & \\
Length $X$ & $14.5 \mathrm{~m}$ \\
Length $Y$ & $13.2 \mathrm{~m}$ \\
Length $Z$ & $14.5 \mathrm{~m}$ \\
Properties & \\
Volume & $55.284 \mathrm{~m}^{3}$ \\
Mass & $1.2715 \mathrm{e}+005 \mathrm{~kg}$ \\
Scale factor value & 1 \\
Statistics & \\
Bodies & 1 \\
Active bodies & 1 \\
Nodes & 76,958 \\
Elements & 40,104 \\
Mesh metric & None \\
Basic geometry options & \\
Solid bodies & Yes \\
\hline
\end{tabular}

of velocity magnitude and the velocity coefficient in the direction of $X, Y$ and $Z$. From this figure, it is observed that the velocity magnitude is maximum when it is farthest away from the center of the tank and is approximately $60 \mathrm{~m} / \mathrm{s}$, whereas it roughly remains constant which is approximately $30-35 \mathrm{~m} / \mathrm{s}$ at other positions of the tank. The red region in the sketches shows the magnitude of velocity at the tank which is interior solid portion of the tank, whereas blue, green and dark blue show the velocity magnitude at the outlet, wall and solid wall, respectively. Figure $8 \mathrm{j}$, k shows the velocity contours through the $X$ and $Z$ directions. From this diagram, it is observed that the part of the tank which is not in direct contact with the air is the
Fig. 8 a Graphical representation of absolute pressure at differ- $\downarrow$ ent points on inlet wall and outlet $(5000 \mathrm{~N})$, b graphical representation of static pressure at different points of inlet, wall and outlet $(5000 \mathrm{~N}), \mathbf{c}$ graphical representation of pressure coefficient at different points on inlet, wall and outlet $(5000 \mathrm{~N})$, d graphical representation of dynamic pressure at different points on inlet, wall and outlet $(5000 \mathrm{~N})$, e graphical representation of total pressure on inlet, wall and outlet $(5000 \mathrm{~N}), \mathbf{f}$ graphical representation of velocity quotient at different points on inlet, wall and outlet (5000 N), g graphical representation of $X$-velocity quotient at different points on inlet, wall and outlet $(5000 \mathrm{~N}), \mathbf{h}$ graphical representation of $Y$-velocity quotient at different points on inlet, wall and outlet (5000 N), i graphical representation of $Z$-velocity coefficient at different points on inlet, wall and outlet $(5000 \mathrm{~N})$, $\mathbf{j}$ velocity vector colored by velocity magnitude of fixed cone roof tank $(5000 \mathrm{~N})$ and $\mathbf{k}$ velocity vectors colored by static pressure of fixed cone roof tank ( $5000 \mathrm{~N})$

least affected by the air velocity whereas the part of the tank with direct contact to the incoming air undergoes maximum effect due to high velocity of the incoming air particles.

\section{Discussion on the results}

The firewater storage tank design based on standards and specifications has shown that the material specifications and allowable stress were within the limits. Also, the maximum allowable stress for the bottom shell courses considering the hydrostatic test condition and the thickness of the shell courses shows that the design of the tank is within the allowable safe limit. The results of the ANSYS and CFD analysis show that the annular plate, bottom plate, roof plate, intermediate wire girders and anchor bolt design are within the allowable limit.

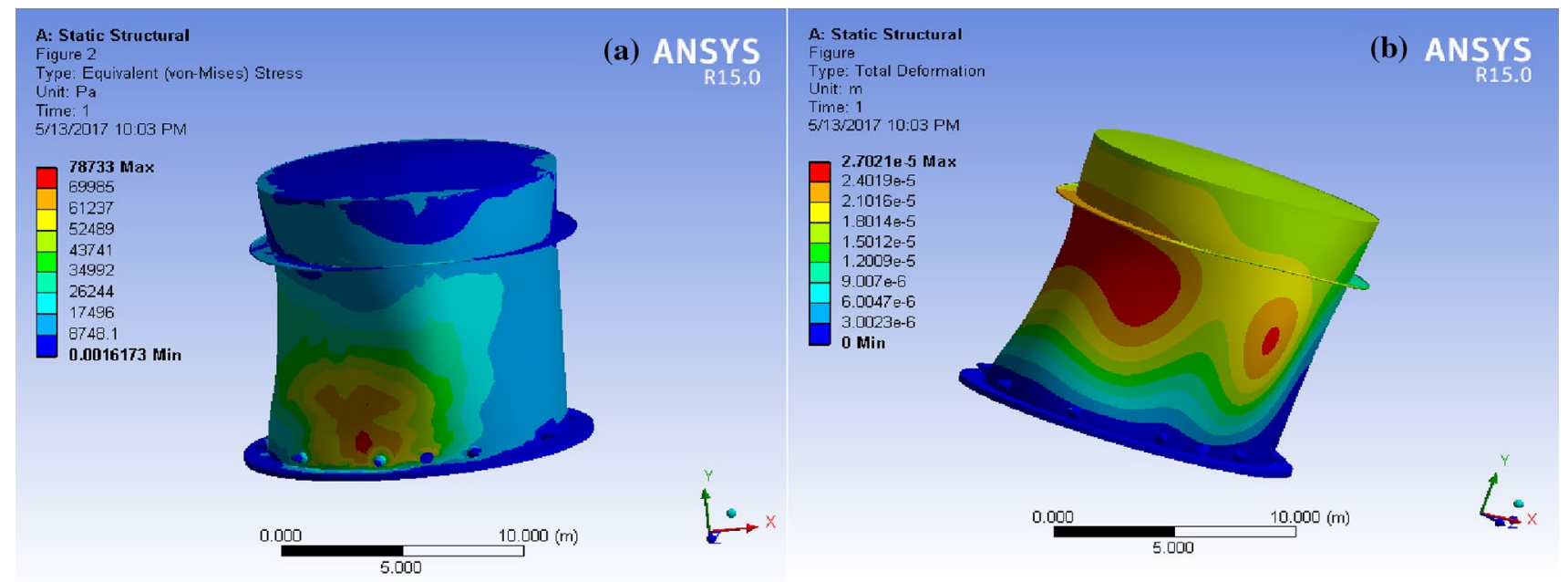

Fig. 7 a Equivalent von Mises stress diagram, b Total deformation diagram 


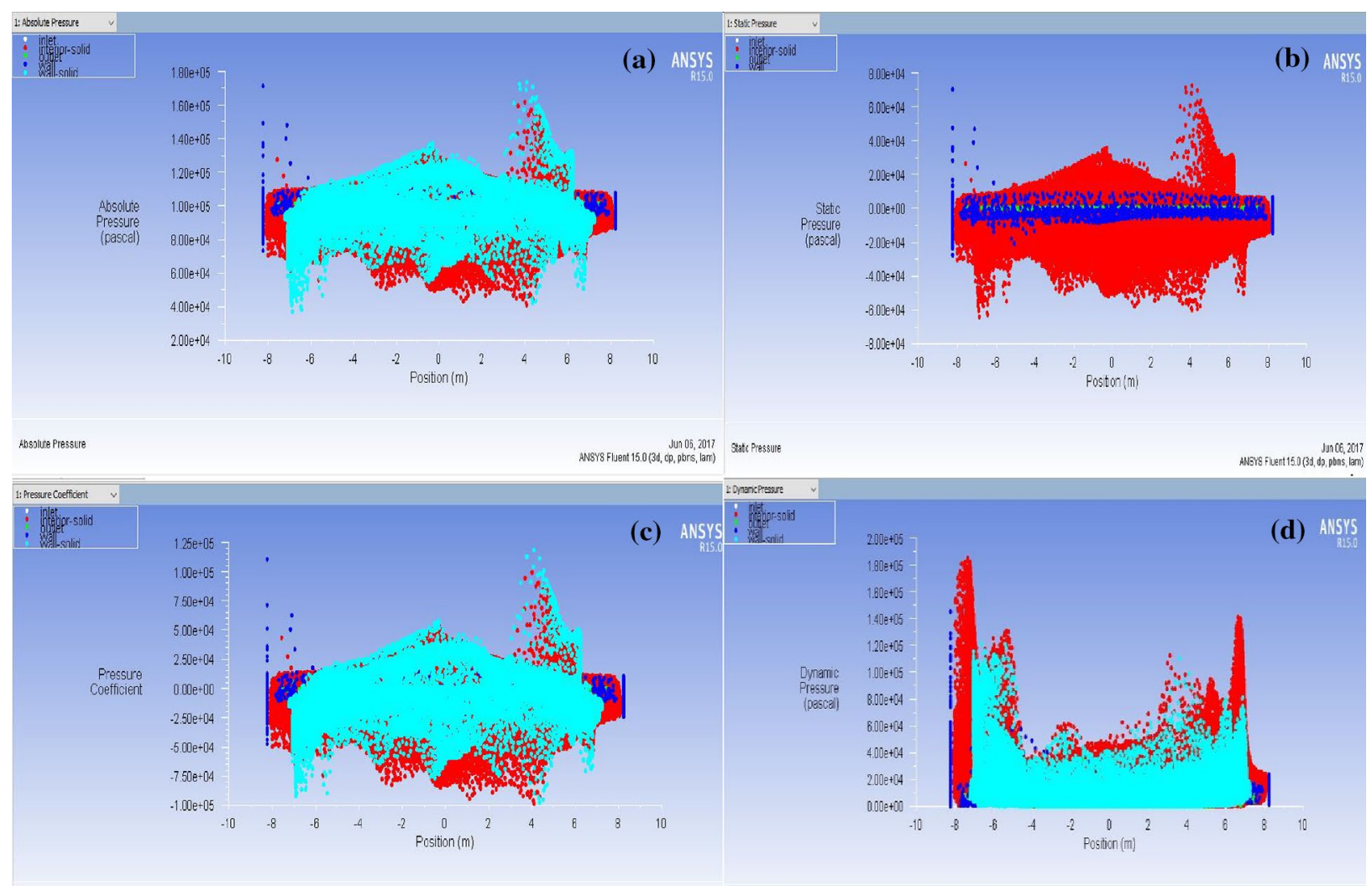

Pressure cceffiliert

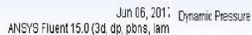

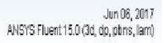

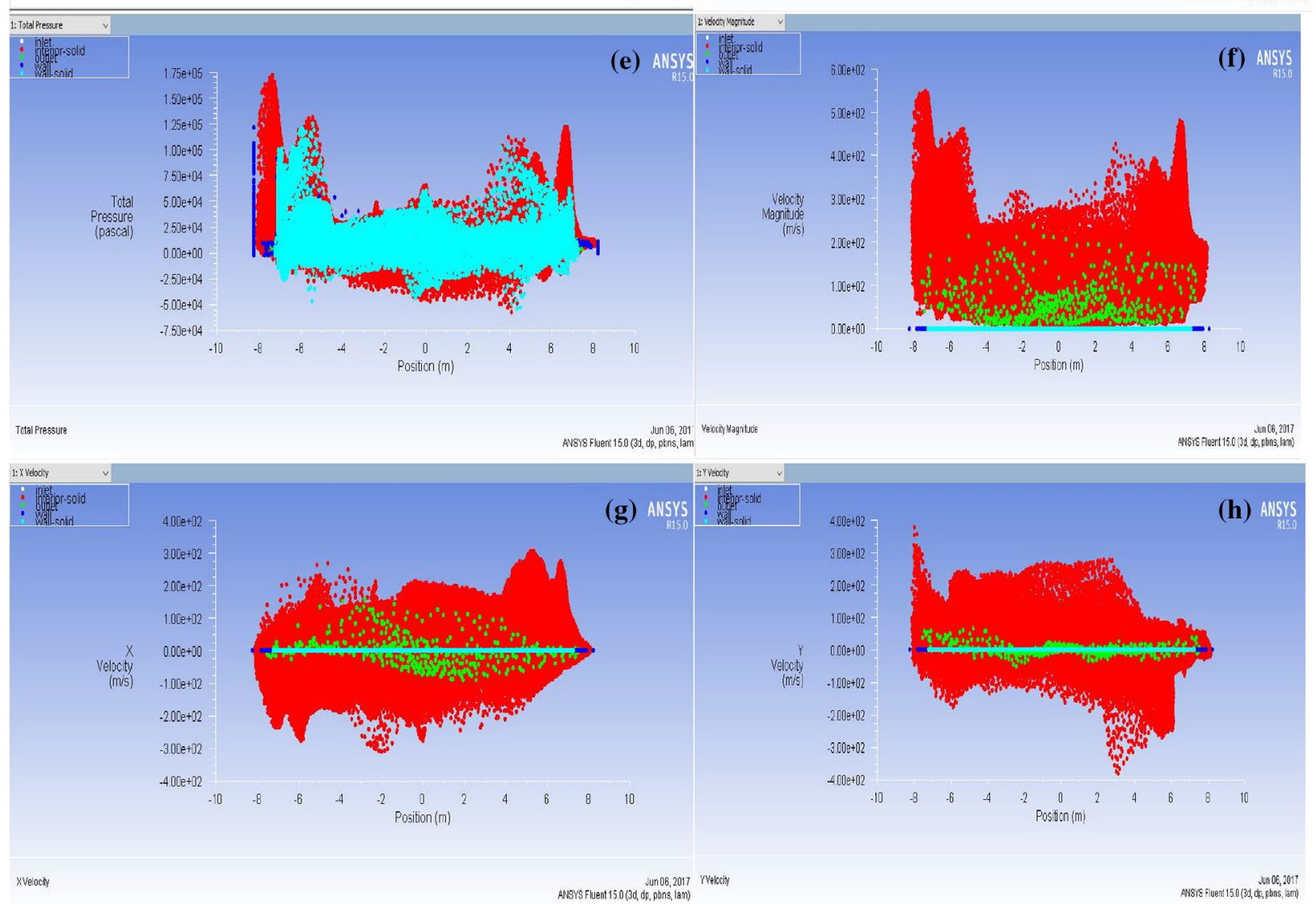




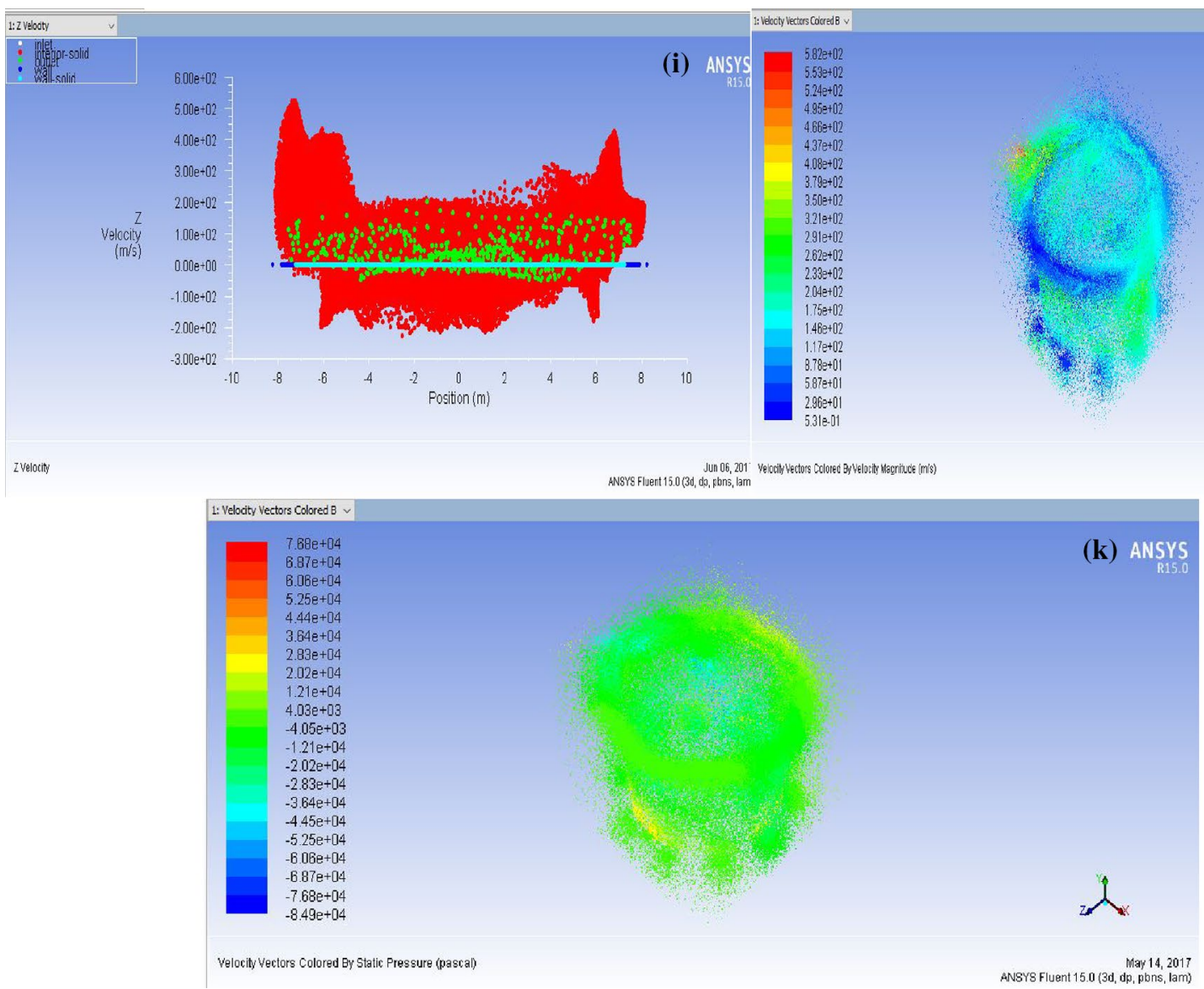

Fig. 8 (continued)

\section{Conclusion}

The main objective of this research paper is to design firewater tank and to perform CFD analysis and ANSYS analysis from the safety point of view. From the software analysis, it is observed that the recent trend is to design larger tanks and as such the seismic design for these larger tanks has become important in terms of safety and the environmental impact. The failure mode of the storage tank subjected to a seismic varies in each structural characteristic coefficient which has been derived from the relationship between the failure mode and the seismic energy transferred to and accumulated in the structure. The possible failure of this firewater tank has been analyzed by applying an internal hydrodynamic pressure, an axial compressive force and the shear force simultaneously. The results obtained from the different standards show that the firewater tank designed is safe from the safety point of view. Also, the results obtained using CFD analysis and ANSYS analysis have shown that design of firewater tank is safe. From both these results, it can be concluded that the firewater tank used have many advantages such as reducing the total cost of the system and it is more reliable for both industries and individual users.

\section{Compliance with ethical standards}

Conflict of interest On behalf of all authors, the corresponding author states that there is no conflict of interest.

\section{References}

1. Scholz M (2014) Firewater storage, treatment, recycling and management: new perspectives based on experiences from the United Kingdom. Water 2014(6):367-380

2. Aware RJ, Mathada VS (2015) Seismic analysis of cylindrical liquid storage tank. Int J Sci Res 4(12):552-557

3. Kronowitt R (1998) Water storage tank. US patent no. 5819773, 13 Oct

4. Ali Roshanfekr (2016) Procedures for designing and assessing the firewater storage tank gravel pad safety. Int J Sci Basic Appl Res 25(2):233-244

\section{SN Applied Sciences}


5. Palmer SC (1994) Stresses in storage tanks caused by differential settlement. Proc Inst Mech Eng Part E J Process Mech Eng 208(1):5-16

6. API 650, Welded tanks for oil storage, 12th edition, March 2013

7. NFPA 22-2013 Edition Standard for Water Tanks for Private Fire Protection
8. American Water Works Association (AWWA) specification tanks, D100, 2011 Edition

9. ANSYS, Inc., ANSYS Fluent 15.0 user's guide 